\section{'Nickels' Almond x Peach Hybrid Clonal Rootstock}

\author{
Dale E. Kester, Richard N. Asay, and Thomas M. Gradziel \\ Department of Pomology, University of California, 1 Shields Avenue, \\ Davis CA 95616
}

Additional index words. interspecific hybrid, Prunus dulcis, Prunus amygdalus, Prunus persica, nematode resistance, tree replant

'Nickels' is a vegetatively propagated almond rootstock clone originating as a hybrid seedling 'PA1-82' from the cross of 'UCD533' almond to 'Nemaguard' peach. Vegetative progeny are uniform, vigorous, highly compatible with almond cultivars, and relatively easy to propagate. Compared with the commercially important 'Hansen 536' rootstock, 'Nickels' is better adapted to current nursery propagation and storage practices as well as to a wider range of California almond production environments, possibly related to its greater winter chilling requirement. 'Nickels' also has a similar range of resistance to nematode species as does the parental 'Nemaguard', which is a widely used rootstock for Prunus tree crops in California. The hybrid vigor of this interspecific rootstock confers greater vigor to the almond scion, making it particularly useful for replant situations where adjacent trees are typically larger and so more competitive.

\section{Origin}

Four types of rootstock are currently used in California almond plantings. 'Lovell' peach rootstock is preferred by growers in the Sacramento Valley due to its general tolerance to heavier soils and its promotion of earlier bearing. 'Marianna 2624' plum rootstock is used on heavy, wet soils and where oak-root fungus is a problem. 'Nemaguard' peach is the most widely planted rootstock, particularly in the San Joaquin Valley with better drained and often sandy soils, due to its field resistance to root knot nematodes (Meloidogyne spp.). 'Nickels' belongs to the most recently developed class of almond rootstock which utilizes almond $x$ peach hybrids to combine nematode and disease resistance with greater scion vigor and earlier bearing (Kester and Grasselly, 1987).

'Nickels' originated from a cross of 'UCD5-33' almond [Prunus dulcis (Mill.) D.A. Webb] to 'Nemaguard' peach [Prunus persica (L.) Batsch] made in 1959 as part of the almond breeding program at the California Agricultural Experiment Station, Univ. of California, Davis. Prunus rootstock devel-

Received for publication 15 Sept. 2000. Accepted for publication 7 May 2001. We gratefully acknowledge the assistance of Tom Aldrich and John Edstrom of the Nickels Estate Research Farm over the many years of rootstock testing. opment was then pursued through two separate strategies. C.O. Hesse and C.J. Hansen identified peach germplasm resistant to root knot nematodes (Meloidogyne javanica and M. incognita) (Sharp et al., 1970). The second approach by D.E. Kester and C.J. Hansen sought to utilize the hybrid vigor of interspecific hybrids between almond $x$ peach to provide vigorous uniform rootstocks for almond (Kester and Hansen, 1966). The latter program also selected hybrid clones that could be readily propagated by hardwood cuttings (Kester and Sartori, 1966; Hansen and Hartman, 1968). From the Hesse- Hansen program, two clonal almond $\mathrm{x}$ peach selections were introduced: 'Hansen 2168' and 'Hansen 536' (Kester and Asay, 1987). Only 'Hansen 536' became an important commercial rootstock for almonds in California and is often being referred to and sold as 'Hansen' rootstock. However, the short dormancy characteristic of the 'Hansen 536' rootstock is associated with higher levels of root-rot fungus infection of bare-root trees in nursery cold- storage, leading to higher tree losses in the orchard following transplanting. In addition, long-term orchard survival of 'Hansen 536' has been shorter than other rootstocks of this type, and a greater sensitivity to wet soils has limited its use primarily to the San Joaquin Valley in California where the annual rainfall is less than in the more northern parts of California.

'Nickels' was selected to overcome these limitations. It was first grown at the Dept. of Pomology orchards at Davis, under the field designation 'PA1-82'. Softwood cuttings were used to produce plants that were tested in greenhouse nematode control tanks maintained by Hesse and Hansen. Cuttings of 'Nickels' as well as 'Nemaguard' controls grown for 8 months in disease screening tanks maintained at temperatures below $25{ }^{\circ} \mathrm{C}$ containing $M$. javanica and $M$. incognita (race 3) isolated from San Joaquin Valley orchards were completely free of galls and so considered to be resistant to immune to these nematodes (Hansen, personal communication). However, gall development on susceptible cultivars (e.g., 'Lovell) indicated that nematode invasion took place under these as well as artificially inoculated soils concluded that 'Nickels' is not immune but possesses levels of field resistance comparable to 'Nemaguard', which is presently the most conditions. Field trials in naturally infested widely planted rootstock for control of Meloidogyne spp. damage in almond and peach (McKenry, personal communication). Propagation tests of 'Nickels' also showed $>60 \%$ rooting success for hardwood cuttings when treated with rooting hormones and fungicides (Hansen and Hartmann, 1968) and planted directly into the nursery row in late fall, as is common practice.

Two long-term orchard plots were established in 1976, one at the Nickels Estate Research Farm (Colusa County, Calif.) in the Sacramento Valley of northern California and the other at the Kenneth Hench Regional Variety Trial (Kern County, Calif.) in the lower San Joaquin Valley of southern California. These included the important almond rootstocks at that time with emphasis on comparing a series of peach $\mathrm{x}$ almond hybrid clones, including 'Nickels'. Tree performance was evaluated over the life of the orchard with tree size and yield data collected in 1988 and 1989. Propagations for the evaluation of tree survivability following different nursery tree storage treatments were made in 1995 , and data on transplant survival were collected in 1996 and 1997.

\section{Description}

As an unbudded plant, 'Nickels' is a large tree with a form intermediate between its parents 'Nemaguard' and almond selection 'UCD5-33'. Fruit bearing habit tends to be like the peach parent with long vigorous shoots which eventually develop shorter spurs. Flowers are borne laterally on long shoots, usually two to three at a node (Fig. 1). About $20 \%$ of buds are produced on short spurs. The overall flower size is greater than that of both parents.

Bloom and leafing-out period is in early to middle March in California, which is later than essentially all of the almond cultivars, and corresponds to about that of 'Nemaguard'. It is much later in bloom than 'Hansen 536' and 'Hansen 2136', due probably to its higher winter chilling requirement. The tree becomes dormant in late October to November, being earlier than that of other almond cultivars and the 'Hansen 536' and 'Hansen 2136' rootstocks.

The bark, buds, and shoots have a rose brown over green coloration that also gives it a reddish look as compared to 'Hansen 536' and 'Hansen 2136'. The flower buds also have a red coloration that extends to the sepals. Petals are dark rose-pink in the bud rather than the white petals typical of almond, and remain pink as they expand, then gradually fade to light pink and almost white by petal drop. Flower appearance is very showy and petals overlap with a rounded to oblong shape and an undulating margin. The endocarp is very hard and peach-like with a pronounced tip (Fig. 1). Leaves are dark green in color, and large and lanceolate in shape, tapering to the apex about $1 / 3$ of the way from the apex. Glands are not prominent, often with two to four globose glands found on the petiole near the blade. 


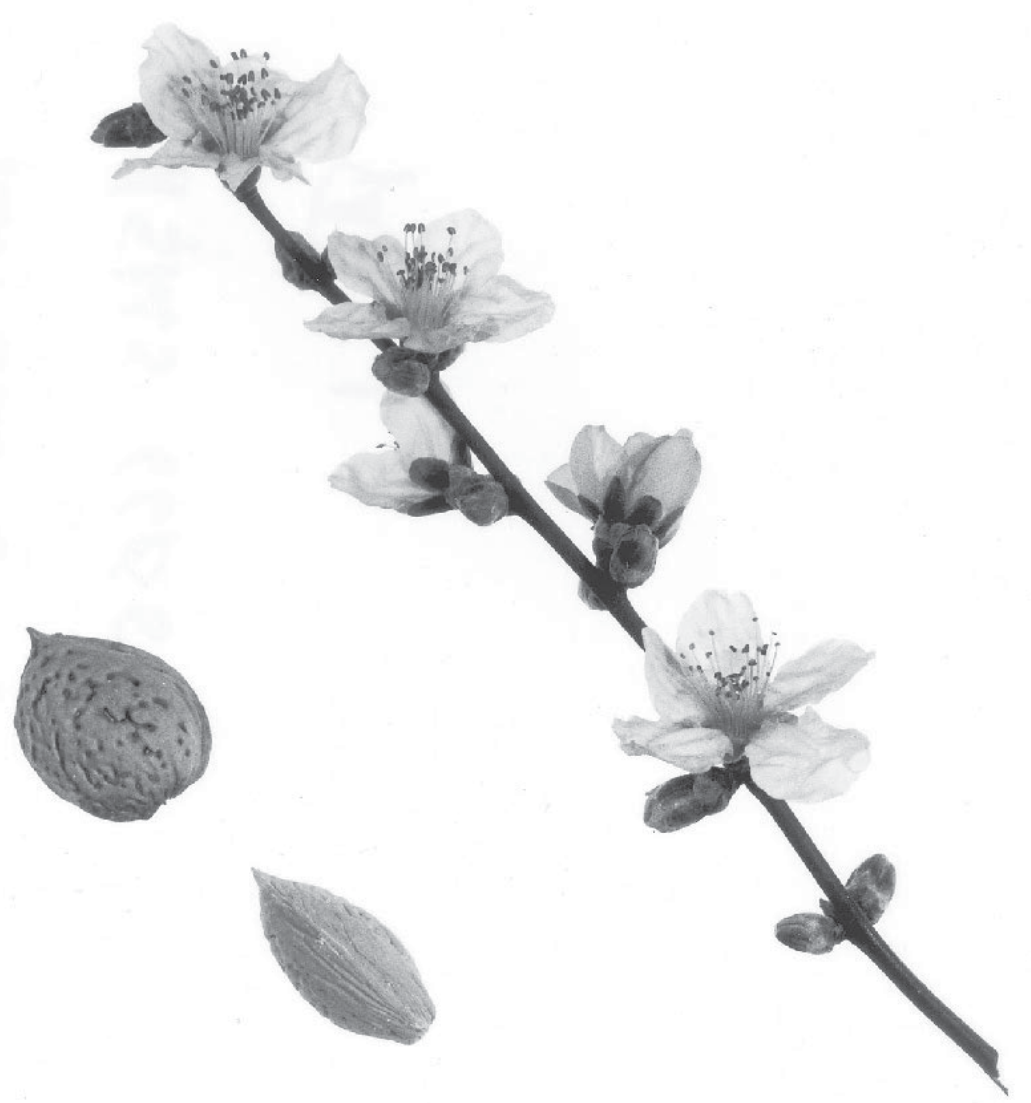

Fig. 1. Appearance of the flower and endocarp for 'Nickels' almond x peach hybrid rootstock.

Table 1. Average 1988 and 1989 tree and nut performance for three commercially important California almond varieties on 'Nickels' and standard 'Nemaguard' rootstocks.

\begin{tabular}{|c|c|c|c|}
\hline & Nemaguard & Nickels & Probability $^{2}$ \\
\hline \multicolumn{4}{|l|}{ Mission } \\
\hline Kernel yield (kg.) & 19.8 & 20.2 & ND \\
\hline Ave. kernel mass (gm DW) & 1.11 & 1.13 & ND \\
\hline Trunk circumference $(\mathrm{cm})$ & 77.8 & 87.3 & $<0.05$ \\
\hline Trunk cross-section $\left(\mathrm{cm}^{2}\right)$ & 487.6 & 612.9 & $<0.05$ \\
\hline Yield per cross-section area & 40.6 & 33.0 & $<0.05$ \\
\hline \multicolumn{4}{|l|}{ Nonpareil } \\
\hline Kernel yield (kg.) & 23.2 & 23.5 & ND \\
\hline Ave. kernel mass (gm DW) & 1.31 & 1.27 & ND \\
\hline Trunk circumference $(\mathrm{cm})$ & 87.3 & 96.3 & $<0.05$ \\
\hline Trunk cross-section $\left(\mathrm{cm}^{2}\right)$ & 612.1 & 749.3 & $<0.05$ \\
\hline Yield per cross-section area & 37.9 & 31.4 & $\mathrm{ND}$ \\
\hline \multicolumn{4}{|l|}{ Ne Plus Ultra } \\
\hline Kernel yield (kg.) & 16.7 & 18.1 & ND \\
\hline Ave. kernel mass (gm DW) & 1.40 & 1.49 & ND \\
\hline Trunk circumference $(\mathrm{cm})$ & 77.63 & 88.56 & $<0.05$ \\
\hline Trunk cross-section $\left(\mathrm{cm}^{2}\right)$ & 486.2 & 631.2 & $<0.05$ \\
\hline Yield per cross-section area & 34.4 & 28.7 & $<0.05$ \\
\hline
\end{tabular}

Table 2. Survival of 'Nonpareil' trees budded in 1995 onto 'Hansen 536' and 'Nickels' rootstocks and planted at the same time but with different pre-transplant practices.

\begin{tabular}{lcccc}
\hline \hline & & \multicolumn{2}{c}{ Survival (\%) after 2 seasons (1997) } & \\
\cline { 2 - 4 } Treatment & No. of trees & Hansen 536 & Nickels & Probability $^{\mathrm{z}}$ \\
\hline Direct planting & 30 & 98 & 97 & ND \\
Short term-storage & 50 & 8 & 43 & $<0.01$ \\
Long-term cold-storage $^{\mathrm{x}}$ & 30 & 16 & 90 & $<0.01$ \\
\hline
\end{tabular}

${ }^{2}$ As determined by Student's $t$ test; ND $=$ no difference.

${ }^{y}$ Stored for $<1$ month with roots held in moist saw-dust at ambient temperatures ranging from 2 to $10^{\circ} \mathrm{C}$. ${ }^{x}$ Held as bare-rooted trees for $>1$ month at 1 to $3{ }^{\circ} \mathrm{C}$.

\section{Performance}

Almond trees evaluated on 'Nickels' rootstock demonstrated good performance over the 20-year evaluation period with no evidence of increased disease susceptibility or rootstock-scion graft-incompatibility when compared with 'Nemaguard' and almond $\mathrm{x}$ peach commercial rootstocks. The 'Nickels' hybrid rootstock conferred increased vigor over 'Nemaguard' as measured in tree trunk circumference or trunk cross-sectional area measured at $30 \mathrm{~cm}$ above the soil line (Table 1). This increased tree vigor has made 'Nickels' and other hybrid rootstocks useful for tree replant situations as the resultant tree is more able to compete with the older, and so larger, adjacent trees. Overall tree yield was not significantly different than on 'Nemaguard' (Table 1), however, yield efficiency was lower than on 'Nemaguard'. Additional field trials have also shown that 'Nickels' has greater resistance to replant-related tree failures (Connell, 2000). The higher survivability of 'Nickels' over 'Hansen 536' following both short term storage (with roots held in moist saw-dust at ambient temperatures typically ranging from 2 to $10^{\circ} \mathrm{C}$ ) as well as long-term cold-storage of bare rooted trees at 1 to $3{ }^{\circ} \mathrm{C}$ (Table 2) demonstrates a greater adaptability of this rootstock to these nursery practices and possibly a greater resistance to soil borne pathogens since root rot organisms appear to be the primary cause of this type of tree decline.

'Nickels' is currently being tested as a rootstock for peach and while long term performance evaluations are not complete, no rootstock-scion incompatibility have been observed with peach cultivars.

Advantages of the 'Nickels' rootstock over the 'Hansen' and similar hybrid rootstocks are longer tree survival in orchards, a wider adaptation to California almond growing areas including the wetter regions of northern California, better compatibility with nursery propagation/storage practices, and vegetative propagation rates comparable to the 'Hansen' rootstocks. The name 'Nickels' was conferred to recognize the contribution of the Nickels Estate Research Farm, which provided land and support for early rootstock test plantings.

\section{Availability}

'Nickels' is available as a licensed (patentpending) cultivar with licenses granted through the Office of Technology Transfer (OTT), Univ. of California, Oakland. Propagation material is distributed as registered virus tested sources through the Foundation Plant Materials Service, Univ. of California, 1 Shields Ave., Davis, CA 95616.

\section{Literature Cited}

Connell, J. 2000. Field evaluation of almond rootstocks, p. 54. In: Proceedings of the 28th annual almond industry conference. Almond Board of California, Modesto, Calif.

Hansen, C.J. and H.T. Hartmann, 1968. The use of 
indolebutyric acid and captan in the propagation of clonal peach and peach-almond hybrid rootstock. Proc. Am. Soc. Hort. Sci. 91:135-140.

Kester, D.E. and R.N. Asay 1987. 'Hansen 2168' and 'Hansen 536'- Two new Prunus rootstock clones. HortScience 21:331-332.

Kester D.E. and C.H. Grasselly. 1987. Almond rootstocks. In: R.C. Rom and R.F. Carlson, (eds.). Rootstocks for fruit trees. Wiley, New York.

Kester, D.E. and C.J. Hansen, 1966. Rootstock potentialities of $F_{1}$ hybrids between peach (Prunus persica L.) and almond (Prunus amygdalus Batsch.). Proc. Amer. Soc. Hort. Sci. 89:100-109.

Kester, D.E. and E. Sartori. 1966. Rootings of cuttings in populations of peach (Prunus persica L.), almond (Prunus amygdalus Batsch) and their $F_{1}$ hybrid. Proc. Amer. Soc. Hort. Sci. 88:219-223.

Sharp, R.H., C.O. Hesse, B.J. Lownsbery, V.G. Perry, and C.J. Hansen. 1970. Breeding peaches for root knot nematode resistance. J. Amer. Soc. Hort. Sci. 94:209-212. 